\title{
Report of the Radionuclides in Nephrourology Committee on Renal Clearance
}

\author{
M.D. Blaufox, Mattias Aurell, Bernd Bubeck, Enza Fommei, Amnon Piepsz, Charles Russell, Andrew Taylor, \\ Henrik S. Thomsen and Duccio Volterrani \\ Department of Nuclear Medicine, Montefiore Medical Park, Bronx, New York; Sahlgrenska Hospital, Groteborg, Sweden; \\ Kantonsspital St. Gallen, St. Gallen, Switzerland; CNR Institute, Pisa, Italy; Academisch Zienkenhuis, Brussels, Belgium; \\ University of Alabama, Birmingham, Alabama; Emory University, Atlanta, Georgia; Herlev Hospital, Herlev, Denmark
}

The need for simple and accurate methods to measure renal function is self-evident. This need increases as techniques for intervention become available. The demand for evaluation of individual kidney function has increased with its role in the diagnosis and follow-up of unilateral renal disease and in decision making for conservative or surgical treatment based on residual renal function. The role of nuclear medicine in this area has been inhibited by confusion about conflicting methodologies. This report is meant to provide guidance to those centers that would like to initiate clearance procedures but have difficulty in choosing appropriate methodology.

Koy Words: renal clearance; glomerular filtration rate; effective renal plasma flow

\section{J Nucl Med 1996; 37:1883-1890}

S Serum creatinine concentration depends on muscle mass and is not usually elevated out of the normal range until the glomerular filtration rate (GFR) has fallen by at least $50 \%$. Endogenous serum creatinine clearance as a measure of GFR is inaccurate $(1,2)$, especially when renal function is low $(3)$ due to a compensatory increase in tubular secretion, which limits its validity as a glomerular filtration marker. Inulin clearance remains the gold standard as a GFR tracer (4), but it is expensive, time-consuming to measure and requires a steadystate plasma concentration and urine collection for the greatest accuracy. In addition, inulin has become increasingly difficult to obtain.

Procedures for urinary clearance, which require the continuous infusion of radiopharmaceuticals and timed urine collection, remain major methods for research purposes. In routine practice, however, single-injection clearance methods (5), which provide greater simplicity and sufficient accuracy to meet clinical demands, are usually adequate.

The radionuclide agent of choice for GFR is ${ }^{51} \mathrm{Cr}$-EDTA because its clearance is considered to be closest to that of inulin. However, ${ }^{99 \mathrm{~m}} \mathrm{Tc}-\mathrm{DTPA}$ clearance correlates well with ${ }^{51} \mathrm{Cr}$ EDTA (6). Some ${ }^{99 m}$ Tc-DTPA formulations have minimized the serum protein binding of the tracer, which is responsible for low plasma clearance $(7-10)$. Both tracers seem reliable for measuring GFR by plasma clearance when it is greater than 30 $\mathrm{ml} / \mathrm{min}$. DTPA is relatively inexpensive, provides a low radiation dose to patients and can be used for gamma camera imaging. When only GFR measurement is required, ${ }^{51} \mathrm{Cr}$ EDTA is an economic and practical alternative where it is available.

Among the plasma clearance techniques, a growing need for simplification has led to the replacement of multicompartmental

\footnotetext{
Received Mar. 22, 1996; revision accepted May 17, 1996.

For correspondence or reprints contact: M. Donald Blaufox, MD, PhD, Professor of Medicine and Radiology, Department of Nuclear Medicine, Montefiore Medical Park, 1695A Eastchester Rd., Bronx, NY 10461.
}

models requiring multiple blood samples with single compartment models that need only two to three blood samples $(10,11-14)$. Further simplified techniques requiring only one blood sample have also been developed. Several studies (1517) have compared simplified one-sample methods with a two-compartment method and reported that the Christensen and Groth iterative method (using a single sample) is more accurate (18). The level of inaccuracy of the Tauxe (19) method for GFR was somewhat higher. A recent study from $\mathrm{Li}$ and Blaufox reached a similar conclusion (20).

The single-sample methods have found a more limited application in children, for whom different equations should theoretically be used, taking into account the variations in anatomic and biologic factors with age. However, Ham and Piepsz (21) demonstrated that in children of various age, the ${ }^{51} \mathrm{Cr}$-EDTA clearance obtained by the two-sample method (2-4 hr) closely correlated with the 2 -hr distribution volume. They applied a linear equation obtained from the whole group and found that the equation could be used to calculate renal clearance in children of all ages, including infants. Groth et al. (22) also have applied their method to pediatric practice.

The level of renal function is an important determinant of the overall accuracy in each method (23), particularly the single sample ones which tend to be inaccurate when the GFR is less than $30 \mathrm{ml} / \mathrm{min}(10,15)$. In the presence of overt renal insufficiency, the method of choice remains the calculation of urinary clearance (24), although delayed single-sample methods have been suggested as an alternative (25).

The need for simplification has led to the introduction of a gamma camera with external counting procedures that offer both simplicity and the estimation of separate kidney function as part of an imaging study. Two types of methods have gained popularity: the first, developed by Piepsz (26) directly yields milliliter per minute GFR as the ratio of the renal upslope to the blood curve after calibration of the precordial curve with a plasma concentration sample. The second one, popularized by Gates (27), relies on the computation of early integral renal counts (as a fraction of the injected dose), which is used with an equation obtained by regression with creatinine clearance to yield total and separate kidney clearances. Camera-based methods are not as accurate as plasma-sample techniques, but their reproducibility appears to be good and they may play an important role in serial monitoring of renal function $(28-30)$. Careful attention to technical details is essential to avoid major errors.

Background subtraction is particularly critical in some methods, since intra- and extravascular activity is rapidly changing (in opposite directions) during the time when individual function is usually calculated and the contribution of each type of activity varies within different regions of interest (31). Moreover, the assumption that the precordial curve is representative 
of the blood disappearance curve is affected also by uncertainty about the contribution of extravascular activity (31). The empirical equations used in the formulas for background correction will be valid as long as the original parameters are used, including the type of background subtraction.

Variability in renal depth may influence the accuracy of uptake calculations especially in the measurement of separate kidney function. Differences in kidney depth greater than $2 \mathrm{~cm}$ have been found only in $1.5 \%$ of patients in a recent series of 201 patients. Therefore, assuming an effective attenuation coefficient for ${ }^{99 \mathrm{~m}} \mathrm{Tc}$ of $0.12 / \mathrm{cm}$, it is unlikely that a relative uptake outside the range $60 / 40$ will reflect differences in kidney depth when the patient is imaged in the supine position (32).

Although GFR is more familiar to most clinicians, other parameters can be used to monitor renal function. Effective renal plasma flow (ERPF) has been estimated by radioisotopic tracers to substitute for urinary clearance of para-amminohippuric acid. This reduces the time required for the study because of faster clearance than GFR agents. Iodine-131-hippuran is still the most widely used tracer for this purpose, particularly in the simplified two blood sample or one-sample procedures $(33,34)$. Recently, the use of another tubular extracted tracer has been proposed, mercaptoacetyltriglycine (MAG3), which has the advantage of being labeled with ${ }^{99 \mathrm{~m}} \mathrm{Tc}$ and is more suitable for renal imaging (35). MAG3 underestimates hippuran clearance by $30 \%-40 \%$ presumably because of its high protein binding which makes its glomerular filtration negligible and also may limit tubular extraction (36-38). Formulas have been derived to obtain ERPF with MAG3, by the use of regression equations derived from paired-tracer studies. Gamma camera methods have also been developed (38). The renal clearance of a pure tubular agent is important irrespective of the possibility of estimating ERPF. Bubeck et al. (39) proposed to describe the clearance of MAG3 as the tubular extraction ratio (TER) to emphasize the potential role of this agent in the follow-up of nephrological diseases in which tubular function is impaired.

More recently, ${ }^{99 m}$ Tc-N,N-ethylenedicysteine $\left({ }^{99 m} \mathrm{Tc}-\mathrm{EC}\right)$ has been introduced by Verbruggen et al. (40) as an alternative to MAG3. The molecule shares with MAG3 the property of being actively extracted by the tubule, but, due to a lesser degree of protein binding, it has a more rapid plasma clearance rate which approaches that of hippuran. The new radiopharmaceutical is easily prepared at room temperature, without the boiling step necessary for MAG3. Preliminary clinical studies $(41,42)$ indicate a close similarity between EC and MAG3 both in renographic curves and renal imaging quality.

\section{RECOMMENDATIONS FOR AN APPROACH TO RENAL CLEARANCES IN NUCLEAR MEDICINE: TECHNIQUE CHOICES}

It is recommended that researchers use the full disappearance curve or a continuous infusion with urine collection for the most reliable estimate of renal clearance. It should always be noted that plasma clearances are indirect and subject to nonrenal variations. In comparison, urinary clearances have the advantage of being direct but subject to problems with urine collection.

\section{Clinical}

In a patient with GFR $\geq 30 \mathrm{ml} / \mathrm{min}$, the single-sample technique is adequate. If the GFR is $<30 \mathrm{ml} / \mathrm{min}$, the primary technique should include urine collection. Urine collection also is indicated in patients with ascites or edema or another expanded body space.
Secondary Technique. A 24-hr specimen using a singlesample technique can be substituted for urine clearance in patients with renal failure. This is discussed below.

\section{RECOMMENDED AGENTS}

\section{GFR}

Primary Agents.Technetium-99m-DTPA, which requires standardization since protein binding varies among different manufacturers and will affect the technique and the need to measure protein free filtrates and ${ }^{51} \mathrm{Cr}$-EDTA which may provide more accurate values for GFR than ${ }^{99 \mathrm{~m}}$ Tc-DTPA, but has the disadvantage of poor imaging characteristics and lack of commercial availability in the United States.

Secondary Agent. The only secondary agent recommended at this time is $\left[{ }^{125} \mathrm{I}\right]$ iothalamate. However, iothalamate, an ionic high-osmolar contrast agent, is no longer approved for intravascular use in Denmark, New Zealand or Ontario.

Effective Renal Plasma Flow. ERPF values can be achieved by using ${ }^{123} \mathrm{I}-$, ${ }^{131} \mathrm{I}$ - or ${ }^{125} \mathrm{I}$-orthoidohippurate.

Tubular Function. Technetium-99m-MAG3 should be used to assess this parameter.

\section{METHODS OF MEASUREMENT \\ GFR}

We recommend that the preferred technique for clinical measurement of GFR be based on the Groth 4-hr methodology. The equations for calculating GFR have been modified by Watson (16) and may be used as shown in the Appendix.

\section{Effective Renal Plasma Flow (Hippuran)}

We recommend that the Tauxe method (34) for measuring ERPF be utilized. The optimum time for a single sample is at 44 min, but the use of a time between 39-49 min will yield acceptable results. The equations and constants for these times are shown in the Appendix.

\section{Tubular Function (MAC3)}

We recommend the use of the Bubeck approach (43) or the Russell equations (44). Russell's approach uses two samples that may provide some additional accuracy under certain circumstances. In most cases, we believe that a single sample would suffice. Like the ERPF measurement, blood sampling should be performed between 39 and 49 min postinjection. Other methods that have been described by Taylor, Piepsz, Muller-Suur and others may also be suitable but are not referenced here. The purpose of this report is to provide guidance in choosing a technique but not to exclude alternatives.

\section{Combined Function}

For the measurement of a combined GFR and ERPF value, we recommend that a sample be obtained at $44 \mathrm{~min}$ to estimate ERPF and a second sample be obtained at 2-3 hr to provide the additional time sample for GFR. The 44-min sample should be used to calculate ERPF or tubular extraction and the 44-min plus the 2- or 3-hr sample be used with the slope technique to determine GFR (20).

\section{Urine Collection Techniques}

Urine collection techniques should be used for patients with severely reduced renal function or in situations where there may be a third space and indirect clearance techniques are not reliable. It is extremely important to note that if there is a nonrenal site for the radiopharmaceutical to enter, any plasma clearance will overestimate the true value.

If a urine collection technique is utilized, urine should be collected at 2-3 hr and 3-4 hr with blood samples at 150 and 
TABLE 1

Minimum Recommended Doses for Clearances Without Imaging in a 70-kg Person

\begin{tabular}{lcc}
\hline \multicolumn{1}{c}{ Tracer } & Megabecquerels & Millicuries \\
\hline Technetium-99m-DTPA & 1 & 0.027 \\
Chromium-51-ETDA & 1 & 0.027 \\
${ }^{123}$ |, ${ }^{125}$ |, ${ }^{131}$ |-orthoiodohippurate & 2 & 0.054 \\
Technetium-99m-MAG3 & 2 & 0.054 \\
\hline
\end{tabular}

$210 \mathrm{~min}$. High urine flow rates are critical. Corrections for sampling time should be made by drawing the slope and estimating the correct sample value. If urine collections are made, residual urine should be estimated if possible. If residual urine is not estimated the potential error may be quite high.

A study of patients with reduced renal function (45) reported that the GFR corrected for residual urine was $56.1 \pm 6.6$ (s.e.) $\mathrm{ml} / \mathrm{min}$ compared to $61.8 \pm 7$ uncorrected.

\section{Correction for Body Size}

We recommend that the plasma concentration of the samples be corrected to a concentration expected for an individual of $1.73 \mathrm{~m}^{2}$ for adults and children in both hippuran and MAG3 studies $(43,46)$. For measurement of GFR in individuals who are greater than or equal to $1.4 \mathrm{~m}^{2}$, the Groth equations are acceptable but may be improved by surface area correction. It has been suggested that the equations of Ham (21) should be used in people less than $1.4 \mathrm{~m}^{2}$ if the clearance is greater than $30 / \mathrm{ml} / \mathrm{min} / 1.73 \mathrm{~m}^{2}$. An alternative approach, still widely used, is the two-sample method with blood samples at about 2 and 4 $\mathrm{hr}$. See the Appendix for special considerations in reference to children.

\section{Individual Renal Function}

The preferred technique for the measurement of individual renal function utilizes camera counts between 1 and 2 or 2.5 min for OIH, MAG3 or OIH. We recommend that any activity less than $1 \mathrm{~min}$ should not be included in the determination of individual renal function, since this represents a significant amount of nonrenal radioactivity. In well-hydrated patients, activity may leave the renal area by $2.5 \mathrm{~min}$ or even sooner.

Secondary Technique. A secondary technique recommended for individual renal function measurement utilizes ${ }^{99 m} \mathrm{Tc}$ DMSA uptake at $2-4 \mathrm{hr}$; or ${ }^{99 \mathrm{~m}} \mathrm{Tc}$-glucoheptonate at $2-4 \mathrm{hr}$ can be used unless obstruction is present which is a contraindication. It is recommended that if any renal pelvic activity is demonstrated at $2 \mathrm{hr}$ on any of these studies, the study should definitely be extended to $4 \mathrm{hr}$.

"DMSA does not use the same transport mechanism as $\mathrm{OIH}$ or MAG3 (47-49). Yee et al. (47) showed that dehydration, mannitol diuresis and changes in urinary $\mathrm{pH}$ influence the DMSA biodistribution. The renal uptake of DMSA decreases by $50 \%$ and the kidney-to-liver ratio falls from $35: 1$ in control rats to $5: 1$ in rats with acid urine. Also, in patients with proximal tubular acidosis, substantially lower renal DMSA uptake has been demonstrated $(50,51)$. In experimental studies, gentamycin and cysplatin toxicity has been shown to impair renal uptake (52)"'.

\section{Background Subtraction}

We could not reach a general consensus on background subtraction. Therefore, we recommend that individual centers decide whether or not to subtract background, but realize that the results be carefully tracked to determine if the background subtraction technique being used is providing appropriate results (54).

\section{GENERAL CONSIDERATIONS}

We recommend that the patients be well-hydrated. The ideal technique would be to determine the specific gravity and hydrate the patient to a specific gravity of less than 1.020. Whether or not this is done, the patients should receive approximately $5-6 \mathrm{ml} / \mathrm{kg}$ of fluid before the clearance study.

Renal Failure. In patients with reduced renal function, alternatives to urine collection may be used (55), although the majority of committee members preferred urine sampling at low levels of renal function. These alternatives are:

Estimated GFR 15-30 ml/min - blood sampling between 3 and $5 \mathrm{hr}$ postinjection.

Estimated GFR $<15 \mathrm{ml} / \mathrm{min}$ - blood sampling between 5 and $24 \mathrm{hr}$ postinjection or only $24 \mathrm{hr}$ postinjection.

These sample times are appropriate for adults only. For a rough estimate of the appropriate time for drawing the blood, the nomogram advocated by Kamper et al. (25) is recommended. This estimate takes the weight, age, sex and serum creatinine level into consideration. The use of the equation can be avoided by drawing a blood sample at $24 \mathrm{hr}$ instead (Table 1).

\section{APPENDIX}

\section{Calculation of the Renal Clearances}

\section{Single-Sample Methods}

GFR. The following approach to measurement of GFR with single sample is taken from a letter to the editor by Watson (16).

The basic equation for single-sample measurement of clearance is:

$$
\mathrm{Cl}=-\ln \left(\mathrm{ECV} / \mathrm{V}_{\mathrm{t}}\right) \cdot \mathrm{ECV} /(\mathrm{t} \cdot \mathrm{g}(\mathrm{t})) . \quad \text { Eq. } 1
$$

$\mathrm{Cl}=$ total ${ }^{51} \mathrm{Cr}$-EDTA (or ${ }^{99 \mathrm{~m}} \mathrm{Tc}$-DTPA) plasma clearance in $\mathrm{ml} / \mathrm{min} ; \mathrm{ECV}=$ extracellular volume in $\mathrm{ml}=8116.6 \cdot$ surface area $\left(\mathrm{m}^{2}\right)-28.2 ; \mathrm{V}_{\mathrm{t}}=$ tracer distribution volume at time $\mathrm{t}$, in $\mathrm{ml}$; and $g(t)=(0.0000017 t-0.0012) \cdot \mathrm{Cl}(-0.000775 \mathrm{t}+1.31)$.

If this equation is rewritten as: $\mathrm{Cl} \cdot \mathrm{t} \cdot \mathrm{g}(\mathrm{t})+\ln \left(\mathrm{ECV} / \mathrm{V}_{\mathrm{t}}\right) \cdot \mathrm{ECV}=$ 0 and we assume $t=240 \mathrm{~min}$, for instance, the equation becomes: $-0.1901 \mathrm{Cl}^{2}+269.8 \mathrm{Cl}+\ln \left(\mathrm{ECV} / \mathrm{V}_{240}\right) \cdot \mathrm{ECV}=0$.

This is a simple quadratic equation and is analogous to the standard form, $a x^{2}+b x+c=0$, with its two solutions:

$x=\left(-b \pm \sqrt{b^{2}-4 a c}\right) / 2 a=(-b / 2 a) \pm \sqrt{b^{2}-4 a c} / 2 a ; \quad$ Eq. 2

The values $a$ and $b$ are constants for a given time $t$, while $c$ is calculated from the measured distribution volume at time $t$ and the predicted ECV.

Table 1 lists values of $a, b$ and $c$ at different values of $t$.

To calculate the total plasma clearance, the above values are introduced into the following formula:

$$
\mathrm{Cl}=(-\mathrm{b} / 2 \mathrm{a})+\sqrt{\mathrm{b}^{2}-4 \mathrm{ac}} / 2 \mathrm{a} .
$$

The first item on the right-hand side of the equation is positive and greater than $650 \mathrm{ml} / \mathrm{min}$ for $\mathrm{t} \geq 180 \mathrm{~min}$, i.e., unphysiologically high for GFR. Therefore, since a is negative, only the positive value of

$$
\sqrt{b^{2}-4 a c}
$$

Eq. 4

need be considered in the second term.

TABLE A1

\begin{tabular}{lccc}
\hline$T(\min )$ & $\mathrm{a}$ & $\mathrm{b}$ & $\mathrm{c}$ \\
\hline 180 & -0.1609 & 210.7 & $\ln \left(\mathrm{ECVN}_{180}\right) \cdot \mathrm{ECV}$ \\
240 & -0.1901 & 269.8 & $\ln \left(\mathrm{ECVN}_{240}\right) \cdot \mathrm{ECV}$ \\
300 & -0.2070 & 323.4 & $\ln \left(\mathrm{ECVN}_{\mathbf{3 0 0}}\right) \cdot \mathrm{ECV}$ \\
\hline
\end{tabular}


Total plasma clearance values can be easily obtained using a pocket calculator or a very simple computer program without the complicated iterative procedure required in the original Groth equations.

In Children. Ham's formula developed for ${ }^{51} \mathrm{Cr}$-EDTA (and probably applicable for ${ }^{99 \mathrm{~m}}$ Tc-DTPA) is GFR $=2.602$ $P_{120}-0.273$, where $P_{120}$ is the plasma concentration at $120 \mathrm{~min}$ postinjection, expressed as the percent injected dose per liter.

Since blood sampling does not occur exactly at $120 \mathrm{~min}$, a small correction factor was introduced, which is valid only if blood sampling occurs in the range of $110-130$ min postinjection:

$$
P_{120}=P_{(t)} \cdot e^{(.008)(t-120)},
$$

where $t$ is the blood sampling time $(110-130 \mathrm{~min})$ and $P_{(t)}$ is the plasma concentration at that time. The final GFR result has to be corrected for body surface area.

\section{Effective Renal Plasma Flow}

Tauxe's formula (34) for hippuran at $44 \mathrm{~min}$ postinjection, modified for normalized plasma concentration is:

$\mathrm{ERPF}=1126.2\left(1-\mathrm{e}^{-0.008\left(\mathrm{ID} / \mathrm{Cn}_{44}-7.8\right)}\right) \mathrm{ml} / \mathrm{min} / 1.73 \mathrm{~m}^{2}$.

Eq. 5

For variable blood sampling times:

$$
\begin{aligned}
& E R P F=F_{\max }\left(1-\mathrm{e}^{-\alpha\left(I D / C \mathrm{n}_{\mathrm{t}}-\mathrm{v}_{\text {lag }}\right)}\right) \mathrm{ml} / \mathrm{min} / 1.73 \mathrm{~m}^{2} . \\
& \mathrm{F}_{\max }=2501.3-108.1 \mathrm{t}+2.656 \mathrm{t}^{2}-0.0206 \mathrm{t}^{3} . \\
& \alpha=0.0236-0.00035 \mathrm{t} . \\
& \mathrm{V}_{\text {lag }}=3.897+0.3 \mathrm{t}-0.0048 \mathrm{t}^{2} .
\end{aligned}
$$

\section{Tubular Function}

Bubeck's formula (43) is:

$$
\operatorname{TER}\left(\mathrm{MAG}_{3}\right)=\alpha+\beta \ln \left(\mathrm{ID} / \mathrm{Cn}_{\mathrm{t}}\right) \quad \mathrm{ml} / \mathrm{min} / 1.73 \mathrm{~m}^{2}
$$

where $\alpha=-517 \mathrm{e}^{-0.011 \cdot \mathrm{t}}$ and $\beta=295 \mathrm{e}^{-0.016 \cdot t}$.

The formula for $44 \mathrm{~min}$ is:

$$
\operatorname{TER}(\text { MAG3 })=-318.6+145.9 \ln \left(\mathrm{ID} / \mathrm{Cn}_{\mathrm{t}}\right) \mathrm{ml} / \mathrm{min} / 1.73 \mathrm{~m}^{2} \text {, }
$$

where ID = injected activity dose (cps); $\mathrm{C}=$ time-specific plasma concentration (cps/liter); $\mathrm{Cn}=\mathrm{C} \cdot \mathrm{BS} / 1.73 \mathrm{~m}^{2}=$ normalized plasma concentration [cps/liter/1.73 $\mathrm{m}^{2}$ ]; and $\mathrm{t}=$ time of blood sampling postinjection ( $\mathrm{min}$ ).

An alternative is the use, in children above $1 \mathrm{yr}$, of a specific pediatric algorithm, developed by the European Pediatric Task Group [Piepsz et al. (59)]:

$$
{ }^{99 m} \text { Tc-MAG3 clearance }=\frac{A}{P(t) \cdot e^{-a(t-35)}}+B,
$$

where $\mathrm{A}=665.89, \mathrm{P}(\mathrm{t})=$ plasma concentration $(\% \mathrm{ID} /$ liter $), \mathrm{a}=$ $0.0298512, \mathrm{t}=$ any time between 30 and $40 \mathrm{~min}$ and $\mathrm{B}=1.89$.

The result of the clearance has to be corrected for body surface.

\section{Two-Sample Method (2,3)}

This method is only required when special accuracy is needed (i.e., for investigational purposes). This method requires the withdrawal of a 90 - or $120-\mathrm{min}$ blood sample in addition to the $240-\mathrm{min}$ sample. Each sample should be processed immediately after withdrawal as described previously. The data are calculated as follows:

$$
G F R=\frac{D \ln \left(P_{1} / P_{2}\right)}{T_{2}-T_{1}} \exp \frac{\left(T_{1} \ln P_{2}\right)-\left(T_{2} \ln P_{1}\right)}{T_{2}-T_{1}},
$$

where $D=$ dose activity $(\mathrm{cpm}) ; P_{1}=$ activity at $T_{1} ; P_{2}=$ activity at $T_{2} ; P_{1}$ and $P_{2}$ are in counts $/ \mathrm{min} / \mathrm{ml}$ (if an ultrafiltrate is used, then this must be multipled by 0.94 ).
In adults, two specific correction factors can be used for having neglected the first exponential.

The first and easiest type of correction is the Chantler's (56) linar correction:

$$
\mathrm{Cl}_{1}=0.93 \times \mathrm{Cl}_{2} \text {, }
$$

where $\mathrm{Cl}_{1}$ is the clearance corrected for the first exponential and $\mathrm{Cl}_{2}$ is the noncorrected clearance.

The second type of correction is the Brochner-Mortensen's (57) quadratic correction:

$$
\mathrm{Cl}_{1}=0.99 \times \mathrm{Cl}_{2}-0.0012 \times \mathrm{Cl}_{2}^{2},
$$

where $\mathrm{Cl}_{1}$ is the clearance corrected for the first exponential and $\mathrm{Cl}_{2}$ is the noncorrected clearance.

In children, similar correction factors, adapted to pediatric ages, can be used:

For example, Chantler's linear correction.

$$
\mathrm{Cl}_{1}=0.87 \times \mathrm{Cl}_{2},
$$

where $\mathrm{Cl}_{1}$ is the clearance corrected for the first exponential and $\mathrm{Cl}_{2}$ is the noncorrected clearance.

The Brochner-Mortensen's quadratic correction (57):

$$
\mathrm{Cl}_{1}=1.01 \times \mathrm{Cl}_{2}-0.0017 \times \mathrm{Cl}_{2}^{2} \text {, }
$$

where $\mathrm{Cl}_{1}$ is the clearance corrected for the first exponential and $\mathrm{Cl}_{2}$ is the noncorrected clearance which should first be corrected for body surface using the Brochner-Mortensen algorithm.

\section{Complete Plasma Curve}

1. Obtain patient's height and weight.

2. Prepare a standard of the radiopharmaceutical to be used (see below).

3. Inject a known amount of radioactivity into the patient's arm.

4. Draw blood samples from the opposite arm at 5, 10, 15, 20, $30,40,60$, and 90 min postinjection for tubular agents. For GFR agents, continue to sample at 120,150 and $180 \mathrm{~min}$.

5. After each sample is drawn, separate the plasma by centrifugation and withdraw $2 \mathrm{ml}$ for counting.

6. Optional: If ${ }^{99 \mathrm{~m}}$ Tc DTPA is used to measure GFR, place an aliquot of the plasma into a Centrifree" micropartition tube to remove any activity that remains protein bound. Count 100 to $200 \mu \mathrm{l}$ of the filtrate and determine protein binding. If it is $\geq$ $10 \%$, the results may be spurious and a correction for protein binding may be necessary (58).

Because normal human plasma is $94 \%$ water and $6 \%$ protein, when the protein is filtered out of $1 \mathrm{ml}$ of plasma, only $0.94 \mathrm{ml}$ of ultrafiltrate remains. This gives rise to the factor of 0.94 in the above equation when ultrafiltrate is used in place of plasma.

The multiple blood sample clearance can be fit by a twoexponential model.

$$
\text { Clearance } \begin{aligned}
(\mathrm{ml} / \mathrm{min})= & (\text { dose injected })\left(b_{1}\right)\left(b_{2}\right) /\left(\left(A_{1}\right)\left(b_{2}\right)\right. \\
& \left.+\left(A_{2}\right)\left(b_{1}\right)\right),
\end{aligned}
$$

where $A_{1}$ and $A_{2}$ are the $y$-axis intercepts of each exponential component and $b_{1}$ and $b_{2}$ are the respective slopes (0.693).

\section{Procedural Details}

Materials Required for Clearance Measurements:

Radiopharmaceutical

$50 \mathrm{ml}$ volumetric flask

$100 \mathrm{ml}$ volumetric flask

$125 \mathrm{ml}$ plastic bottles w/caps (2)

Marking pen 
Glass counting vials (2)

$1 \mathrm{ml}$ tuberculin syringe (1)

Eppendorf, clay adams or equivalent pipette

Water

Baxter minivolume extension set (T-Connector, $15 \mathrm{~cm}$ ) (Baxter

Healthcare Corporation, Deerfield, IL 60015)

\section{Preparation of Technetium-99m Standards for Clearance Measurements}

1. Using the marking pen, label the $50 \mathrm{ml}$ volumetric flask with the following information: Stock Solution (Date).

2. Fill the 50-ml volumetric flask half full of water.

3. Use a tuberculin syringe to withdraw an aliquot from the radiopharmaceutical solution. Do not exceed $1.5 \mathrm{mCi}$ or well counter deadtime count losses may occur.

4. Add water to bring the syringe volume to $1.0 \mathrm{ml}$.

5. Assay this syringe in the dose calibrator and record the activity in the syringe as the Activity of standard on the Worksheet. Use military time; i.e.,1:20 p.m.should be recorded on the WORKSHEET and entered into the computer as 13:20.

6. Transfer the syringe contents, flushing at least once into the volumetric flask; then fill the volumetric flask with water to the $50 \mathrm{ml}$ level. Cap the volumetric flask, shake gently for at least $5 \mathrm{sec}$ and attach a radioactive materials label.

7. Assay the emptied syringe in the dose calibrator to determine residual activity. Again, note the Time and measured Residual syringe activity on the worksheet.

8. Label the $100-\mathrm{ml}$ volumetric flask with the following label: (Radiopharmaceutical) Standard Solution (Date).

9. Fill the $100-\mathrm{ml}$ volumetric flask half full with water.

10. Carefully pipette (use an Eppendorf pipette or equivalent) $1.0 \mathrm{ml}$ of the current Stock Solution into the $100-\mathrm{ml}$ volumetric flask labeled Standard solution. Note: To ensure accurate pipette volume delivery, the tip must first be primed by drawing and expelling solution. Do not attempt to mix the solution using the pipette tip as stirrer.

11. Fill the flask to $100 \mathrm{ml}$ with water, cap the flask and shake gently for $5 \mathrm{sec}$ and attach a radioactive materials label.

12. Carefully pipette (use Eppendorf pipette or Clay Adams pipette or equivalent) $1.0 \mathrm{ml}$ of the current Standard Solution into a glass counting vial. Use a clean pipette tip. Do not use the same pipette tip as was used in step 10. Cap the vial tightly and label as "(Radiopharmaceutical) STD \#1 (Today's Date)."

13. Repeat step \#12 for STD \#2.

14. Repeat step \#12 STD \#3.

15. Set counting vials aside for later counting with plasma samples.

Note: These three Standard Count Vials (STD \#1 and \#3) are to be recounted for each clearance measurement performed on that same day. Substantial variations in counts between standards indicates a pipetting error and new standards should be made up.

\section{Procedure for Dose Injection}

1. Start an i.v. and attach a very short piece of tubing with an injection port such as the Baxter minivolume extension set (T-Connector, $15 \mathrm{~cm}$ ) (Baxter Healthcare Corporation, Deerfield, IL 60015).

2. Attach dose to a three-way stopcock which has a $10-\mathrm{ml}$ saline syringe attached to one of the ports and contains approximately $10 \mathrm{cc}$ of $0.9 \%$ saline for injection.

3. Inject the dose through the three-way stopcock.

4. Flush the dose injection syringe twice by drawing saline into the dose syringe and injecting into the patient. This will be followed by injecting the remainder of the saline through the three-way stopcock.

5. Remove and assay syringe, stopcock and i.v. tubing for residual activity.

\section{Procedure for Blood Sampling}

1. The injection site should not be used to obtain the blood sample.

2. Insert an i.v. line for drawing blood into the vein, preferably using a 18-20 gauge syringe to minimize hemolysis.

3. Attach a three-way stopcock to the i.v. line.

a. Attach a $10-\mathrm{ml}$ syringe containing heparinized saline.

b. To the third port, attach a syringe for the blood sample.

4. Depending on the flow through the three-way stopcock, approximately $45 \mathrm{sec}$ before the time the blood sample is needed, start to withdraw blood back into the heparinized saline syringe to clear the line of heparin.

5. After approximately $15 \mathrm{sec}$, switch the stopcock so that approximately $5 \mathrm{ml}$ of blood can be withdrawn into the blood sample collection syringe.

6. Withdraw blood, timing it so that the midpoint of the blood collection is at the time the sample was collected. If it is not at the correct time, record the ACTUAL TIME when the midpoint of the sample was obtained.

7. At the end of the blood draw, switch the three-way stopcock back so that heparinized saline can be injected back into the patient. Inject approximately $5 \mathrm{ml}$ of heparinized saline to clear out the stopcock and the tubing.

8. The blood should be injected into a tube containing ACD (anticoagulant citric dextrose) or heparin to prevent clotting.

9. Clean out the three-way stopcock with sterile cotton swabs to remove any residual blood and radioactivity.

10. Replace as necessary the heparinized syringe with a new syringe containing heparinized saline.

11. Repeat the procedure for all subsequent blood samples.

12. The anticoagulated blood should be injected into a centrifuge tube and spun to separate the red cells from the plasma.

13. An Eppendorf pipette (or equivalent) should be used to pipette $1.0 \mathrm{ml}$ of plasma into the counting vial. Do not distrub the interface between the plasma and red cells. If enough plasma remains, pipette a second sample.

14. For GFR measurements, it may be necessary to utilize protein free ultrafiltrate using the Centrifree' micropartition centrifuge tube (Amicon Centrifree Micropartition System, Amicon Corp., Danvers, MA).

\section{Procedure for Ultrafiltration (Optional)}

1. Fill Centrifree micropartitiion tube assembly with approximately $1 \mathrm{ml}$ of plasma.

2. Place filled device in fixed-anglehead centrifuge. Be sure centrifuge is balanced.

3. Centrifuge for $15 \mathrm{~min}$ at a speed not to exceed $2000 \mathrm{~g}$. Note: The Centrifree apparatus must be centrifuged in an anglehead centrifuge because a swinging bucket head will result in inadequate filtration.

4. When centrifuge stops, remove the filtrate cup containing the clear, colorless ultrafiltrate and pipette immediately. Pipette $100 \mu \mathrm{l}$ from each assembly into test tubes labeled ultrafiltrate. Cap each tube and count immediately. Record counts and the time each sample was counted. 
Simplified GFR Measurement

Quality Control:

1. The standard and ultrafiltrate activities (if any) should be corrected for decay.

2. Background activity should be measured and subtracted from each standard.

3. The three separate standards should be averaged to get a final value.

\section{Caution}

Well counters can easily be overloaded by the levels of radioactivity used for imaging techniques. This must be avoided by diluting the sample, decaying it, or using small aliquots. Depending somewhat on the instrument, no more than perhaps $0.3 \mu \mathrm{Ci}$ should be placed in the counter. One way to achieve this is to dilute a duplicate of the dose to $100 \mathrm{ml}$ in a volumetric flask, transfer $1 \mathrm{ml}$ of that to a second $100 \mathrm{ml}$ volumetric flask, and then count $0.1 \mathrm{ml}$ of both the twice diluted dose and the patient's plasma.

\section{Sample Worksheets}

See pages 1894 and 1895 .

\section{REFERENCES}

1. Brochner-Mortensen J, Rodbro P. Selection of routine method for determination of glomerular filtration rate in adult patients. Scand J Clin Lab Invest 1976;36:35-43.

2. Sawyer WT, Canaday BR, Poe TE. A multicenter evaluation of variables affecting the predictability of creatinine clearance. Am J Clin Pathol 1982;78:832-838.

3. Jagenburg R, Attman P-O, Aurell M, Bucht $\mathrm{H}$. Determination of glomerular filtration rate in advanced renal insufficiency. Scan J Urol Nephrol 1978;12:133-137.

4. Price $\mathbf{M}$. Comparison of creatinine clearance to inulin clearance in the determination of glomerular filtration rate. $J$ Urol 1972;107:339-340.

5. Sapirstein LA, Vidt DG, Mandel MJ, Hanusek G. Volumes of distribution and clearances of intravenously injected creatinine in the dog. Am J Physiol 1955;181: 330-336.

6. Hilson AJW, Mistry RD, Maisey MN. Technetium-99m-DTPA for the measurement of glomerular filtration rate. Br J Radiol 1976;49:794-796.

7. Carlsen JE, Moller ML, Lund JO, Trap-Jensen J. Comparison of four commercial technetium-99m(Sn)DTPA preparations used for the measurement of glomerular filtration rate: concise communication. $J$ Nucl Med 1980;21:126-129.

8. Russel CD, Bischoff PG, Rowell KL . Quality control of technetium-99m-DTPA for measurement of glomerular filtration: concise communication. $J$ Nucl Med 1983;24: 722-727.

9. Rehling M, Moller ML, Thamdrup B, et al. Simultaneous measurement of rena clearance and plasma clearance of technetium- $99 \mathrm{~m}$-labeled diethylenetriamine pentaacetate, ${ }^{51} \mathrm{Cr}$-labeled ethylenediamine-tetra-acetate and inulin in man. Clin Sci 1984; 66:613-619.

10. Fleming JS, Wilkinson J, Oliver RM, et al. Comparison of radionuclide estimation of glomerular filtration rate using technetium- $99 \mathrm{~m}$ diethylenetriaminepentaacetic acid and chromium-51 ethylenediaminetetraacetic acid. Eur J Nucl Med 1991;18:391-395.

11. Russell CD. Optimum sample times for single-injection, multisample renal clearance methods. J Nucl Med 1993;34:1761-1765.

12. Brochner-Mortensen $\mathrm{J}$. Current status on assessment and measurement of glomerular filtration rate. Clin Physiol 1985;5:1-17.

13. Waller DG, Keast CM, Fleming JS, et al. Measurement of glomerular filtration rate with technetium-99m-DTPA: comparison of plasma clearance techniques. $J \mathrm{Nucl}$ Med 1987;28:372-377.

14. Aurell M, Ditzel J. Renal clearance of ${ }^{51} \mathrm{Cr}$-EDTA-complex. A comparison between continuous infusion and single injection techniques. Seventh International Congress Clin Chemistry, Geneva/Evian (1969) 1970;3:405-413.

15. Picciotto G, Cacace G, Cesana P, et al. Estimation of chromium-51 ethylenediamine tetra-acetic acid plasma clearance: a comparative assessment of simplified techniques. Eur J Nucl Med 1992;19:30-35.

16. Watson WS. A simple method of estimating glomerular filtration rate. Eur J Nucl Med 1992;19:827.

17. Rehling M, Rabol A. Measurement of glomerular filtration rate in adults: accuracy of five single-sample plasma clearance methods. Clin Physiol 1989;9:171-182.

18. Christensen AB, Groth S. Determination of ${ }^{99 \mathrm{~m}} \mathrm{Tc}$-DTPA clearance by a single plasma sample method. Clin Physiol 1986;6:579-588.

19. Tauxe WN. Determination of glomerular filtration rate by single-plasma sampling technique following injection of radioiodinated diatrizoate. $J$ Nucl Med 1986;27:45-50.

20. Li Y, Lee HB, Blaufox, MD. A comparison of single sample methods for calculating GFR [Abstract]. J Nucl Med 1994;35(suppl):5.

21. Ham HR, Piepsz A. Estimation of glomerular filtration rate in infants and in children using a single-plasma sample method. $J$ Nucl Med 1991;32:1294-1297.

22. Aasted $M$, Groth $S$. Chromium-51-EDTA clearance determined by one plasma sample in children. Clin Physiol 1984;4:75-83.

23. Sennewald $K$, Taylor A. A pitfall in calculating differential renal function in patients with renal failure. Clin Nucl Med 1993;18:377-381.
24. LaFrance ND, Drew HH, Walser M. Radioisotopic measurement of glomerular filtration rate in severe chronic renal failure. $J$ Nucl Med 1988;29:1927-1930.

25. Kamper AL, Nielsen SL. Chromium-51-EDTA plasma clearance in severe renal failure determined by one plasma sample. Scand J Clin Lab Invest 1989;49:555-559.

26. Piepsz A, Dobbeleir A, Erbsmann F. Measurement of separate kidney clearance by means of ${ }^{99 m}$ Tc-DTPA complex and a scintillation camera. Eur $J$ Nucl Med 1977;2:173-177.

27. Gates GF. Glomerular filtration rate: estimation from fractional renal accumulation of 99m Tc-DTPA. Am J Roentgenol 1982;138:565-570.

28. Gates FG. Split renal function testing technetium-99m-DTPA: rapid technique for determining differential filtration. Clin Nucl Med 1983;8:400-407.

29. Chachati A, Meyers A, Godon JP, Rigo P. Rapid method for the measurement of differential renal function: validation. $J$ Nucl Med 1987;28:829-836.

30. Klingensmith WC, Briggs DE, Smith WI. Technetium-99m-MAG3 renal studies: normal range and reproducibility of physiologic paramenters as a function of age and sex. J Nucl Med 1994; 35:1612-1617.

31. Peters AM, Bell SD, Gordon I, et al. Effective background correction on separate technetium-99m-DTPA renal clearance. $J$ Nucl Med 1991;32:362-363.

32. Taylor A, Lewis C, Giacometti A, et al. Improved formulas for the estimation of renal depth in adults. $J$ Nucl Med 1993;34:1766-1769.

33. Blaufox MD, Merrill JP. Simplified hippuran clearance. Measurement of renal function in man with simplified hippuran clearances. Nephron 1966;3:274-281.

34. Tauxe WH, Dubovsky EV, Kidd TJ, et al. New formulas for the calculation of effective renal plasma flow. Eur J Nucl Med 1982;7:51-54.

35. Fritzberg AR, Kasina S, Eshima D, et al. Synthesis and biological evaluation of technetium-99m-MAG3 as a hippuran replacement. $J$ Nucl Med 1986;27:111-116.

36. Taylor A, Eshima D, Fritzberg AR, et al. Comparison of iodine-131 OIH and technetium-99m-MAG3 renal imaging in volunteers. $J$ Nucl Med 1986;27:795-803.

37. Bubeck B, Brandau W, Weber E, Kalble T, Parekh N, Georgi P. Pharmacokinetics of technetium-99m-MAG3 in humans. J Nucl Med 1990;31:1285-1293.

38. Eshima D, Taylor A. Technetium- $99 \mathrm{~m}$ mercaptoacetyl-triglycine: update on the new ${ }^{99 m}$ Tc renal tubular function agent. Semin Nucl Med 1992;22:61-73.

39. Bubeck B, Brandau W, Eisenhut $M$, et al. The tubular extraction rate (TER) of technetium-99m-MAG3: a new quantitative parameter of renal function. $\mathrm{Nucl}$ Compact 1987;18:260-267.

40. Verbruggen AM, Nosco DL, Van Nerom CG, et al. Technetium- $99 \mathrm{~m}-\mathrm{L}, \mathrm{L}$-ethylenedicysteine: a renal imaging agent. I. Labeling and evaluation in animals. $J$ Nucl $\mathrm{Med}$ 1992;33:551-557

41. Szilvasi, I, Kornyei J, Nagy Z. Technetium-99m-EC kit for dynamic renal scintigraphy. First clinical results [Abstract]. Eur J Nucl Med 1992;19:617.

42. Ozker K, Onsel C, Kabasakal L, et al. Technetium-99m-N,N-ethylenedicystein. A comparative study of renal scintigraphy with technetium-99m-MAG3 and iodine-131OIH in patients with obstructive renal disease. $J$ Nucl Med 1994;35:840-845.

43. Bubeck B. Renal clearance determination with one blood sample: improved accuracy and universal applicability by a new calculation principle. Semin Nucl Med 1993;23: $73-86$.

44. Russell CD, Taylor AT, Dubovsky EV, Eshima D. A single injection, two-sample method for measuring renal technetium-99m-MAG3 clearance in both children and adults $\mathrm{Nucl}$ Med Biol 1995; 22:55-60.

45. Fotopolos A, Blaufox MD, Lee HB, Lynn R. Effect of residual urine on apparent renal clearance in patients with reduced function. In: $\operatorname{xxxxxx.~Radionuclides~in~Nephrourol-~}$ ogy. xxxxx:xxxxx;1994;163-167.

46. Russell CD, Taylor AT, Dubovsky EV. Measurement of renal function with technetium-99m-MAG3 in children and adults $J$ Nucl Med 1996;37:588-593.

47. Yee CA, Lee HB, Blaufox MD. Technetium-99m-DMSA renal uptake: influence of biochemical and physiological factors J Nucl Med 1981;22:1054-1058.

48. Moretti JL, Rapin JR, Saccavini JC, et al. 2-3 Dimercaptosuccinic-acid chelates. 2. Renal localization. Int J Nucl Med Biol 1984;11:275-279.

49. Goldraich NP, Alvarenga AR, Goldraich IH, etal. Renal accumulation of ${ }^{99 m}$-TcDMSA in the artifically perfused rat kidney $J$ Urol 1985;134:1282-1286.

50. Van Luyk WHJ, Ensing GJ, Piers DA. Low renal uptake of ${ }^{99 \mathrm{~m}} \mathrm{Tc}$-DMSA in patients with proximal tubular dysfunction. Eur J Med 1983;8:404-405.

51. Provoost ApP, Van Aken $M$. The effect of maleate induced proximal tubular dysfunction on the renal handling of technetium-99m-DMSA in the rat [Abstract]. J Nucl Med 1984;35:25.

52. Yamada M, Tanada S, Murase K. Discrepancy in renal uptake of technetium- $99 \mathrm{~m}$ DMSA and creatinine clearance in a rat with drug induced nephrotoxicity. $J \mathrm{Nucl} \mathrm{Med}$ 1992;32:1106.

53. Muller-Suur R. Radiopharmaceuticals: their intrarenal handling and localization. In Murray IPC, Ell PJ, eds. Nuclear Medicine in clinical diagnosis and treatment 1994;1:205.

54. Blaufox MD. Procedures of choice in renal nuclear medicine. $J$ Nucl Med 1991;32: 1301-1309.

55. Kampman J, Siersback-Nielsen K, Kristensen M, Hansen JM. Rapid evaluation of creatinine clearance. Acta Med Scand 1974;196:517-520.

56. Chantler C, Barratt TM. Estimation of glomerular filtration rate from plasma clearance of ${ }^{51} \mathrm{Cr}$ edetic acid Arch Dis Child 1972;47:613-617.

57. Brochner-Mortensen J. Routine methods and their reliability for assessment of glomerular filtration rate in adults. Dan Med Bull 1978;25:181-202.

58. Shattuck L, Eshima D, Hansen L, Taylor A. The effects of protein binding on the renal extraction of technetium-99m-MAG3 and iodine-131-OIH [Abstract]. $J$ Nucl Med 1994;35(suppl):264-265.

59. Piepsz A, Gordon I, Hahn K, Kolinska J, Kotzerke J, Sixt R. Determination of technetium-99m-mercaptoacetylglycine plasma clearance in children by means of a single blood sample: a multicenter study. Eur J Nucl Med 1993;20:244-248. 